Research Article

\title{
Shaking Table Test Study on Flexible and Rigid Immersed Tube Tunnel in Liquefiable Soil Layer
}

\author{
Zhiyong Ouyang $\mathbb{D}^{1},{ }^{1}$ Peijie Li, ${ }^{1}$ Jie Cui, ${ }^{2}$ Ruofan Luo, ${ }^{1}$ and Dandan Yuan ${ }^{3}$ \\ ${ }^{1}$ College of Civil Engineering, Jiaying University, Meizhou, 510405, China \\ ${ }^{2}$ School of Civil Engineering, Guangzhou University, Guangzhou, 510006, China \\ ${ }^{3}$ Jiangmen Architectural Design Institute Ltd. Co., Jiangmen, China \\ Correspondence should be addressed to Zhiyong Ouyang; 52424848@qq.com
}

Received 14 January 2020; Revised 5 July 2020; Accepted 3 August 2020; Published 27 August 2020

Academic Editor: Alessandro Palmeri

Copyright (C) 2020 Zhiyong Ouyang et al. This is an open access article distributed under the Creative Commons Attribution License, which permits unrestricted use, distribution, and reproduction in any medium, provided the original work is properly cited.

\begin{abstract}
To study the seismic response law of the immersed tunnel under different structural stiffnesses, three groups of shaking table models of immersed tunnel are carried out, including free-field model, flexible tunnel model, and rigid tunnel model. The similarities and differences of the pore water pressure and acceleration time-history between the free site and liquefiable soil layer around the flexible and rigid immersed tube tunnel are analyzed. The results show that, compared with the soil layer at the same position in the free-field, both the amplitude of acceleration and frequency component in the surrounding soil layer are affected by the stiffness of tunnel, and the influence comes greater with the larger stiffness of tunnel. When the input amplitude of seismic ground motion is small, the soil layer in the free field and the flexible tunnels share the same acceleration amplification law. The development law of pore pressure in the soil layer of test 1 was similar to test 2 but was quite different from test 3 . Specifically, when the tunnel stiffness is smaller, the surrounding soil layer is easier to liquefy, with greater influence of the tunnel stiffness on the development law of pore pressure in the surrounding soil layer. The lower the soil buried depth is, the faster the pore pressure dissipates. The growth rate of tunnel strain is related to the stiffness of the structure. Generally speaking, the strain growth rate of the structure with smaller stiffness is higher under moderate earthquakes. The smaller the tunnel stiffness is, the more adaptable the tunnel is to the movement of the surrounding soil layer.
\end{abstract}

\section{Introduction}

In recent years, although scientific researchers and engineering technicians in various countries have researched more deeply on the seismic safety of underground structures, especially tunnel structures, they have not attached enough importance to the seismic performance of underground structures due to their small quantity in use and superiority in seismic performance over aboveground structures. However, more and more earthquake data and disasters show that underground structures would also be seriously damaged under the action of earthquakes. From the previous earthquake disasters, the main factors causing the destruction of underground structures can be divided into the following two types [1]: the first is the foundation failure during earthquakes, such as liquefaction and flow of soil layer, instability of slope, and earthquake fault and the second is the excessive deformation of some parts of underground structures under the action of earthquake, which means when the earthquake occurs, the stratum surrounding the underground structure is in a stable state, and it is believed that the destruction is caused by the deformation along with the soil mass. Therefore, the geological conditions around tunnels may directly affect how the surrounding media influence the tunnels. In most cases, with the same ground motion effect, the stiffer the soil mass is, the smaller the deformation, and the safer the structure is. For example, after the earthquake in Taiwan in 1999, only 33.9\% of the tunnels in the high-quality soil were destroyed, while 94.2\% were damaged in the low-quality one. Moreover, with the same geological conditions, the stiffness of tunnels is also one of the important factors in seismic performance. With 
the same deformation, the stiffness may directly influence the stress on structures. The forces causing the soil deformation include the active Earth pressure and the passive stratum resistance resulting from tunnel deformation. Taken to extremes, if the tunnels are absolutely stiff, the load applied by the soil around on the tunnels has no effect on the structural deformation; if the soil around is absolutely stiff, the tunnel structure means nothing. In reality, the two extreme situations do not exist. Both the tunnels and soil are stiff to some extent.

At present, the commonly used practical seismic design methods for underground structures mainly include response displacement method, free-field deformation method, and equivalent lateral force method. These methods are generally accepted by engineers because of their simple theoretical knowledge, small calculation process and workload, and easy determination of calculation parameters. However, these methods are all simplified and assumed, such as ignoring the interaction between soil and structure and the influence of structural rigidity, which would bring some errors to the calculation results.

The research shows that the stiffness of the underground structure itself is also one of the important factors in seismic performance $[1,2]$. That is, under the action of earthquake, the deformation of the structure is mainly determined by the deformation of the surrounding strata and the stiffness of the structure itself. At the same time, the deformation of the structure may cause the redistribution of the stress of the structure and the surrounding strata, and the deformation of the stratum is affected by the stiffness of the structure. Therefore, the relative rigidity of the two is the foundation of the interaction between structure and stratum [3]. For example, [4] assume that the cross section of the underground structure was circular, deduced the seismic response models of the two-dimensional and three-dimensional underground structures by using the pseudostatic method, and analyzed it. The results showed that the soil characteristics and the relative rigidity between soil and structure are the reasons for the structural distortion and deformation. Reference [5], taking the interaction between soil and structure into consideration, analyzed the deformation of tunnels with circular cross section and rectangular ones, concluding that the relative stiffness between tunnels and soil may largely influence the calculation. The authors of [2] used pseudostatic and dynamic methods to analyze the underground structure, reaching the conclusion that the relative stiffness between soil and structure has an important impact on the seismic performance of the underground structure when the buried depth of the underground structure is small. The authors of [6] introduced the concept of flexibility ratio to study the influence of the relative stiffness between soil and structure on the seismic performance of underground structures and gave the criterion of relative flexibility. The authors of [7], aiming at rectangular underground structures, discussed in detail the influence of soil layer stiffness and the relative stiffness between soil and structure on the seismic response of underground structures by using the quasistatic method. They displayed the curves about how the displacements of the underground structures changed with the relative stiffness between soil and structure changing under three different earthquake waves and concluded that when the flexibility ratio is less than one, it would hugely influence the structural displacements. The authors of [8] used the dynamic finite element method to discuss the influence of the relative stiffness between the tunnel structure and the surrounding soil layer on the seismic response of the structure and obtained the functional relationship between the internal force of the structure and the compliance ratio, which suggests that with higher compliance ratio, the internal force of the structure would be less. The authors of [9] applied the two-dimensional finite difference unit model to explore the factors influencing the performance of segment lining structure and concluded that the rotational, radial, and axial stiffness plays an important role in the seismic performance of tunnels, with radial stiffness more influential in positive bending ratio than in negative bending. The authors of [3], considering the interaction and deformation coordination between the lining and the stratum in soft soil stratum, pointed out two concepts-antieccentric-compression stiffness in tunnel lining and relative stiffness between tunnel and stratum-and built the theoretical system of relative stiffness ratio considering the rotational stiffness of segment joint. With regard to the tunnel design theory nowadays, they also suggested that the tunnel stiffness should be reduced to adapt to the stratum deformation. The authors of [10] derived the analytical solution of seismic response of long tunnel on nonuniform foundation under the action of sinusoidal shear motion. The results show that the sharp transitions in structure stiffness and/or ground properties have a significant influence on the seismic response of the tunnel. Most of the researchers above explored the influence of the relative stiffness on the structural internal force and deformation theoretically and numerically, but almost none of them paid attention to the influence on the dynamic characteristics of soil (such as the spectrum characteristics of soil, the development law of pore pressure, and the constitutive relation). Besides, nowadays researchers mainly focus on the influence of the relative stiffness of soil and structure on shield tunnel but seldom study that on immersed tube tunnel.

The construction of immersed tube tunnel is simple and time-saving. It is also adaptable to various geological and hydrological conditions, with minimal interference to shipping. These strengths make it the first choice for crossriver and cross-sea tunnels. However, it is often located in a complex marine environment and susceptible to earthquakes. Once a disaster occurs, the damage of immersed tube tunnel may not only cause major accidents, but also have a huge impact on the regional economy. In order to ensure the safety of the immersed tube tunnel under earthquake, the accuracy of its seismic design method is even more important, and the rigidity of the tunnel is one of the important factors that affect its accuracy. Therefore, this paper discusses the influence law of the relative stiffness between soil and structure on the seismic response of immersed tube tunnel, providing a reference for seismic analysis and design. There are three main methods to study this problem, namely, prototype observation, model test, 
and numerical simulation. Among them, the prototype observation method is difficult to realize due to its high requirements for data acquisition. Due to different selection of parameters and calculation models, the results of numerical simulation methods may differ greatly. However, shaking table model tests can reproduce the seismic process of underground structures in a short period of time and intuitively displayed the seismic response law of underground structures and the mechanism and form of seismic damage, which makes it widely adopted [11-14]. Therefore, in this paper, we carried out shaking table tests on flexible tunnel and rigid tunnel in liquefiable free site and liquefiable soil layer, respectively, to analyze the pore water pressure, acceleration time-history, and structural strain in liquefiable soil layer under three different working conditions. The purpose is to discuss the dynamic response characteristics of foundation soil and the response characteristics of immersed tube tunnels with different rigidity during site liquefaction and to reveal the earthquake disaster process and failure mechanism of immersed tube tunnels with different rigidity in liquefiable site.

\section{General Situation of Experiment}

Taking the Hong Kong-Zhuhai-Macao submarine immersed tube tunnel project as the research background, shaking table tests were carried out on free site immersed tube tunnels with different stiffness, respectively. In order to consider the influence of tunnel stiffness and tunnel joint stiffness, three groups of shaking table tests were designed in the test, namely, free-field shaking table test in saturated sand, flexible tunnel shaking table test in saturated sand, and rigid tunnel shaking table test in saturated sand. The influence of the above factors on the dynamic response characteristics of foundation soil and tunnel was compared and studied.

\section{Experimental Design}

This experiment was carried out on a large-scale three-dimensional simulated seismic vibration table of the Institute of Engineering Mechanics, China Seismological Bureau (Harbin). The vibration table was mainly composed of foundation tabletop, vibration exciter, servo valve controller, oil source, and data acquisition and analysis system. The specific parameters are shown in Table 1. And the model box used in the test was a laminated shear model box, which can obviously reduce the interference of the reflected wave generated by the vibration wave on the box wall when the vibration occurs and has better lateral restraint on the soil in the model box. The laminated shear model box consisted of 15 layers of steel frames, each of which can move in the horizontal direction. The overall size was length $\times$ width $\times$ height: $3.70 \mathrm{~m} \times 2.40 \mathrm{~m} \times 1.70 \mathrm{~m}$, as shown in Figure 1.

3.1. Test Similarity Relation. To truly reproduce the destruction process of the structure caused by earthquake action, it is necessary to make the test model and prototype as similar as possible in the test design. According to the
TABLE 1: Technical parameters of the earthquake simulation shaking table.

\begin{tabular}{lc}
\hline Indicators & Technical parameter \\
\hline Peak load & $350 \mathrm{Kn}(35 \mathrm{ton})$ \\
Table size & $5 \mathrm{~m} \times 5 \mathrm{~m}$ \\
Direction of vibration & $X, Y, Z$ \\
Maximum acceleration & $X, Y ; 1.0 \mathrm{~g} ; Z: 0.7 \mathrm{~g}$ \\
Maximum speed & $X, Y: 50 \mathrm{~cm} / \mathrm{s} ; Z: 40 \mathrm{~cm} / \mathrm{s}$ \\
Maximum displacement & $X, Y: \pm 8 \mathrm{~cm} ; Z: \pm 5 \mathrm{~cm}$ \\
Frequency range & $0.5 \sim 40 \mathrm{~Hz}$ \\
Maximum overturning moment & $735 \mathrm{kN} \mathrm{m}$ \\
\hline
\end{tabular}

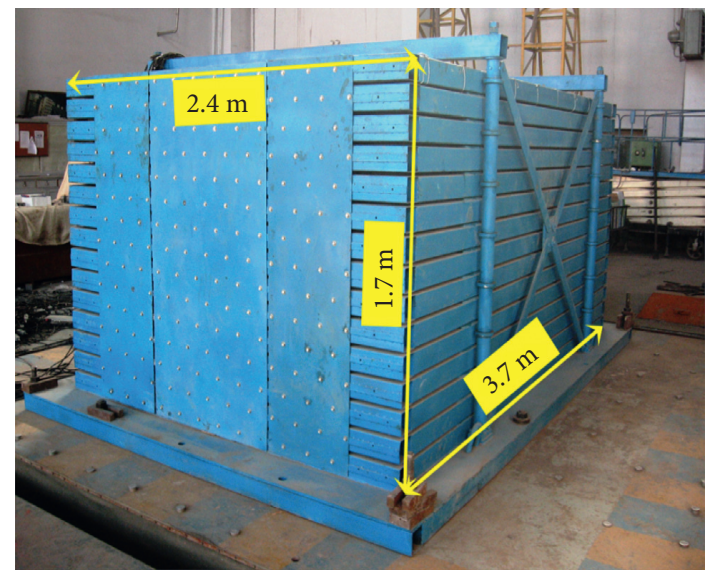

FiguRE 1: Laminated shear model box.

Buckingham $\pi$ theorem and the main purpose of the test (to study the failure mechanism of the tunnel), the structural similarity relation was the major similarity relation of the test, and the tunnel model could meet the similarity ratio relation of density through additional artificial mass. The similarity relation can be expressed as follows:

$$
\sigma=f(\sigma, L, E, \rho, t, r, v, a, g, \omega) .
$$

Formulas such as $\sigma, L, E, \rho, t, r, v, a, g$, and $\omega$ are dynamic stress, length, elastic modulus, density, time, displacement, velocity, acceleration, gravitational acceleration, and circular frequency in turn. The length $L$, density $\rho$, and elasticity models $E$ are basically unknown. The relevant parameters of the similarity ratio of the tests are shown in Table 2.

3.2. Model Making and Design. As the microconcrete is similar to the ordinary concrete and is beneficial to realize the similarity rate of the model as similarly as possible, the materials used for the tunnel structure in this experiment were microconcretes and galvanized lead wires, where the mixing ratio of the microconcretes was cement: lime: water: coarse sand $=1: 0.6: 0.5: 5$, and the forced steel bar and stirrup in the structure were galvanized lead wires with diameters of $2 \mathrm{~mm}$ and $1 \mathrm{~mm}$, respectively.

According to the form of immersed tunnel joints, tunnels can be divided into semirigid tunnels, rigid tunnels, and flexible tunnels. The rigidity of joints in rigid tunnels is 
TABLE 2: Similitude relations and ratios of the model system.

\begin{tabular}{|c|c|c|c|c|}
\hline Item & Symbol & Similitude relation & Tunnel ratio & Soil ratio \\
\hline Geometry & $L$ & $L_{r}$ & $1 / 30$ & $1 / 4$ \\
\hline Elasticity modulus & $E$ & $E_{r}$ & $1 / 4$ & $1 / 4$ \\
\hline Mass density & $\rho$ & $\rho_{r}$ & 5 & 1 \\
\hline Displacement & $d$ & $d_{r}=L_{r}$ & $1 / 30$ & $1 / 4$ \\
\hline Acceleration & $a$ & $a_{r}=E_{r} \rho_{r}^{-1} L_{r}^{-1}$ & 1.5 & 1 \\
\hline Time & $t$ & $t_{r}=E_{r}{ }^{-0.5} \rho_{r}{ }^{-1} L_{r}{ }^{-1}$ & 0.149 & $1 / 2$ \\
\hline Frequency & $\omega$ & $\omega_{r}=t_{r}^{-1}$ & 6.711 & 2 \\
\hline Pore water pressure & $u$ & $u=L_{r} a_{r} \rho_{r}$ & - & $1 / 4$ \\
\hline Shear wave velocity & V & $V_{r}$ & - & $1 / 2$ \\
\hline Stress & $\sigma$ & $\sigma_{r}=E_{r}$ & $1 / 4$ & $1 / 4$ \\
\hline
\end{tabular}

consistent with that of pipe sections while the rigidity of joints in flexible tunnels is generally smaller than that of pipe sections, especially the longitudinal tensile rigidity. In order to study the response of the tunnel stiffness to the tunnel and its surrounding soil layers, two tunnel models with different stiffness were made, and the dynamic responses of free-field test were compared. In order to facilitate test comparison, the design depth, dry density, tunnel buried depth, and ground motion input of the three groups of tests were consistent. The three groups of tests are described as follows:

(1) Test 1 is a free-field shaking table test of saturated sand. In order to fully saturate the sand, a water pipe was preembedded in the inner side of the model box when the soil layer was tamped into the layers, and the input of water quantity was controlled to ensure that the water could fully permeate at each position of the sand. When the water exceeded the surface layer of the sand surface, it would be stopped $s$ and stand there for two days until the sand was fully saturated. Before the test, water was added $230 \mathrm{~mm}$ above the surface of the sand (Figure 2).

(2) Test 2 is a shaking table test of a flexible immersed tube tunnel in saturated sand. The flexible immersed tube tunnel consisted of pipe segments and pipe segment joints. The test model consisted of three pipe sections and two joints, with the pipe section 0.5 meters long, 1.26 meters wide, 0.38 meters high, and the pipe wall 30 millimeters thick (Figure 3(a)). Square steel plates were preembedded in the pipe section ports to facilitate the connection between the pipe sections, as shown in Figure 3(b). The total weight of each pipe section was about $180 \mathrm{~kg}$, and the increased counterweight of each pipe section was $150 \mathrm{~kg}$ according to the similarity ratio. Pipe section joints are generally composed of reinforced concrete shear keys and two water-stops. Due to the limitation of the model scale and the fact that the shear keys are very small and easy to crush after reducing the scale, which makes it difficult to reflect the actual shear key characteristics, the joint was simplified in this test, with natural rubber selected as the main material to make the joint, as shown in Figure 3(c). The crosssectional dimension of the rubber joint was the same as that of the preembedded square steel plate of the pipe section, so the assembly of the model could be completed only by connecting the steel plate of the pipe section with the rubber through bolts in the process of splicing the pipe sections (Figure 3(d)). The rigidity of the rubber joint in the flexible tunnel was about 0.1 times of the pipe section based on calculation. The soil in the test was tamped and formed in four layers, with the thickness of each layer being about $0.3 \mathrm{~m}$. After tamping and forming each layer of soil, water was poured into the model box until the water surface rose to the surface of the layer of soil, and the next layer of soil followed. After filling the soil layer to the design buried depth of the tunnel, the connected model was placed, and then the soil was backfilled. With all the soil backfilled and the foundation soil fully saturated, the surface of the foundation soil was covered with $0.23 \mathrm{~m}$ of water after the soil was saturated and consolidated.

(3) Test 3 is a shaking table test of a rigid immersed tube tunnel in saturated sand. The rigid tunnel was $1.8 \mathrm{~m}$ long, $1.26 \mathrm{~m}$ wide, and $0.38 \mathrm{~m}$ high. In order to consider the stiffness of the tunnel itself and the impact of the stiffness of the tunnel joints, the wall thickness of the rigid tunnel section was $50 \mathrm{~mm}$. The model was cast at one time and there was no joint in the middle (Figure 4). The total weight of the rigid tunnel was 1.1 ton, and the increased counterweight was 1 ton based on calculation according to the similarity ratio, as shown in the following figure. Based on calculation, the bending rigidity (joint rigidity) of the rigid tunnel section in this experiment was about 1.5 times as that of the flexible tunnel section, while the shear rigidity was about 2 times. The operation process of soil was the same as that of test 2 .

3.3. Sensor Arrangement. To obtain the comparative test results, the sensors and observation surfaces were arranged at the same positions in the three groups of tests, as shown in Figure 5 (only the sensor arrangement and the position map of observation surfaces in test 2 are given due to limited space). In Figure 5, a1 to a5 are acceleration sensors of observation surface 1. P1 to P5 are pore pressure sensors in observation surface 1 , and $\mathrm{S} 1$ to $\mathrm{S} 6$ are structural strain gauges in observation surface 1. 


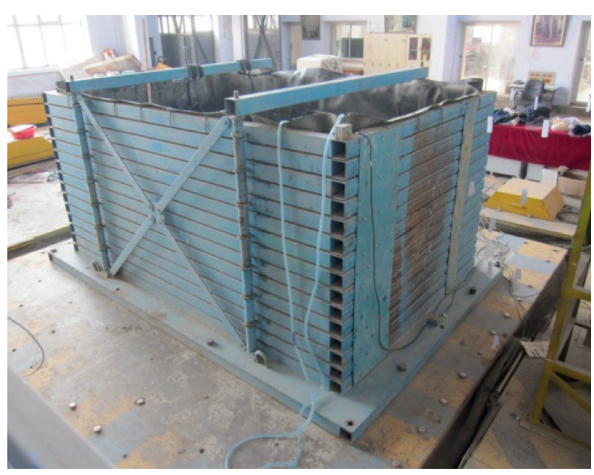

(a)

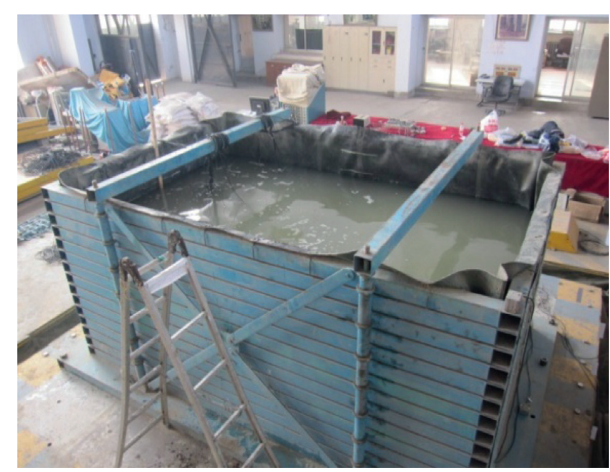

(b)

FIGURE 2: Free-field model of test 1.
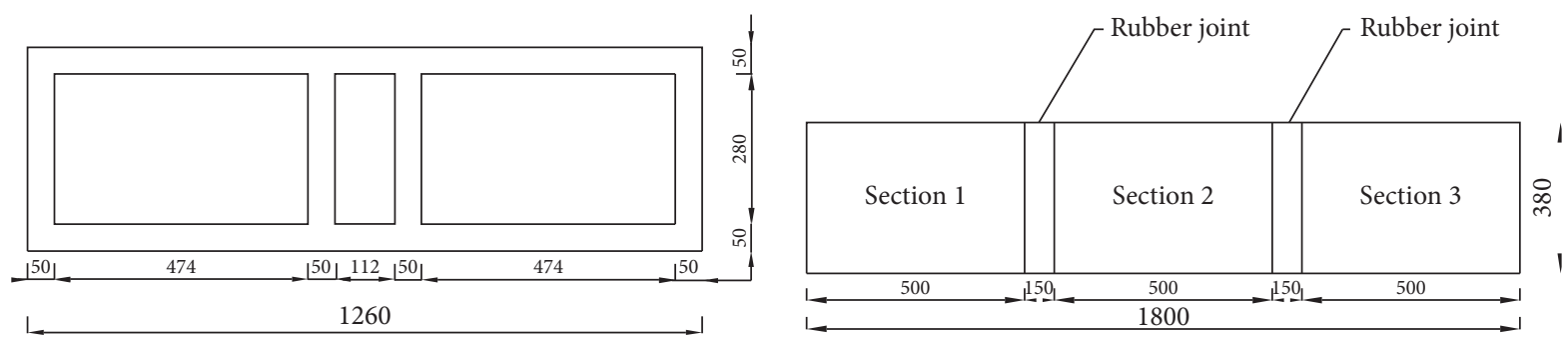

(a)

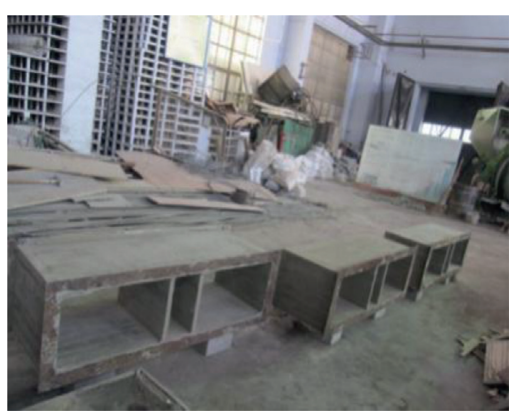

(b)

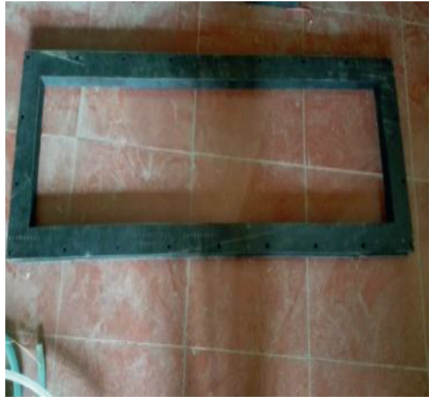

(c)

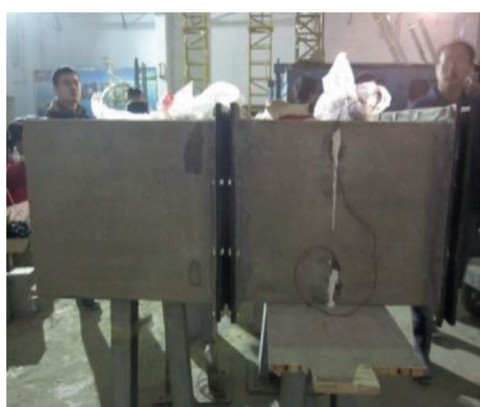

(d)

Figure 3: Flexible tunnel model of test 2.

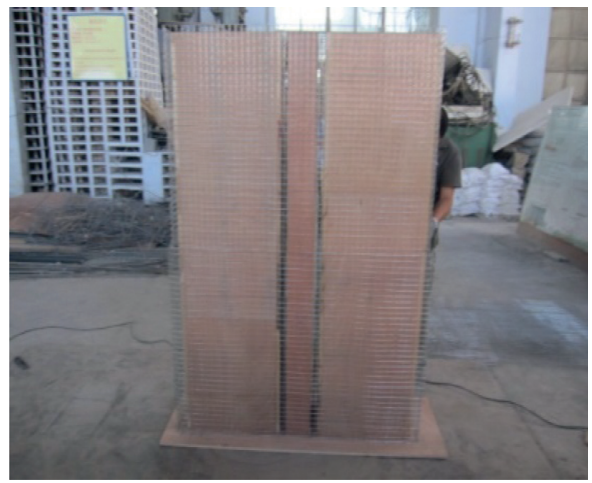

(a)

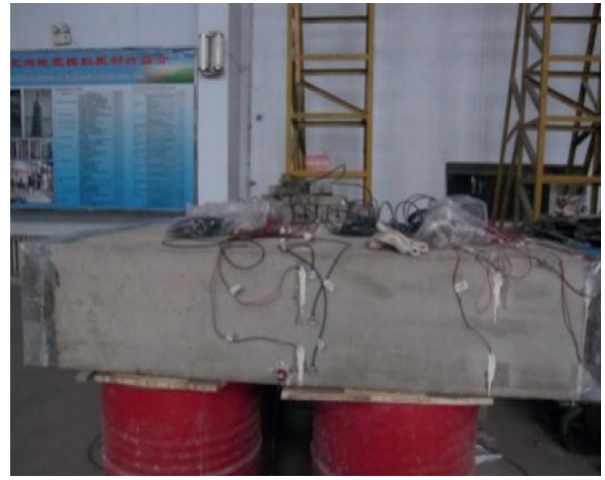

(b)

Figure 4: Rigid tunnel model of test 3. 

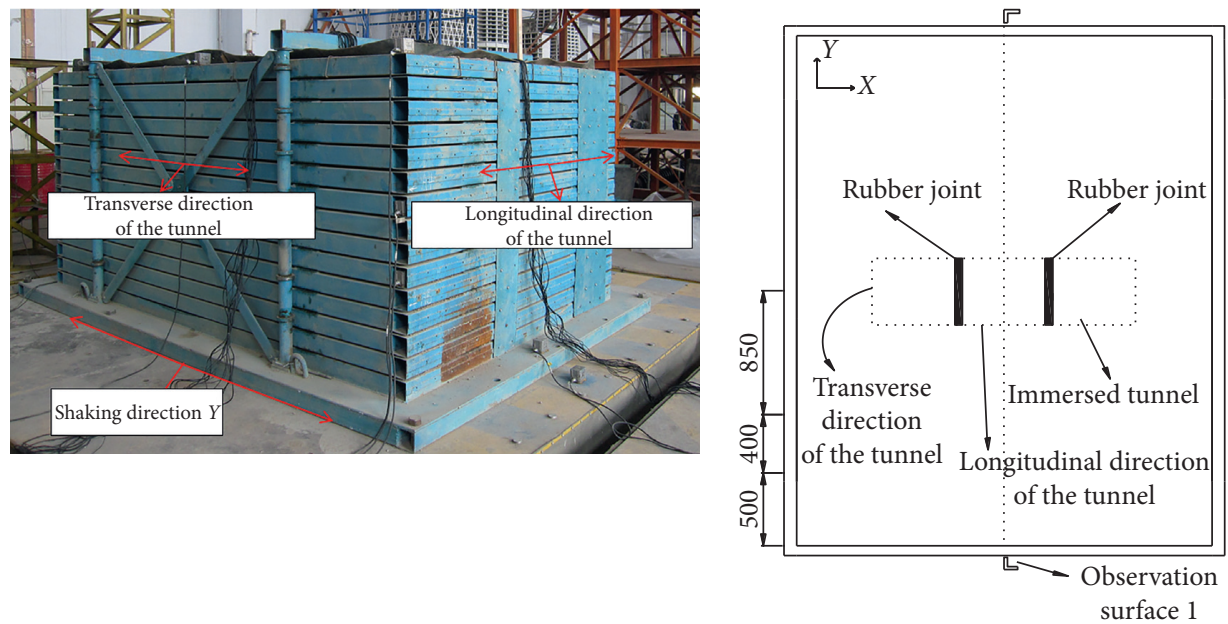

(a)

(b)

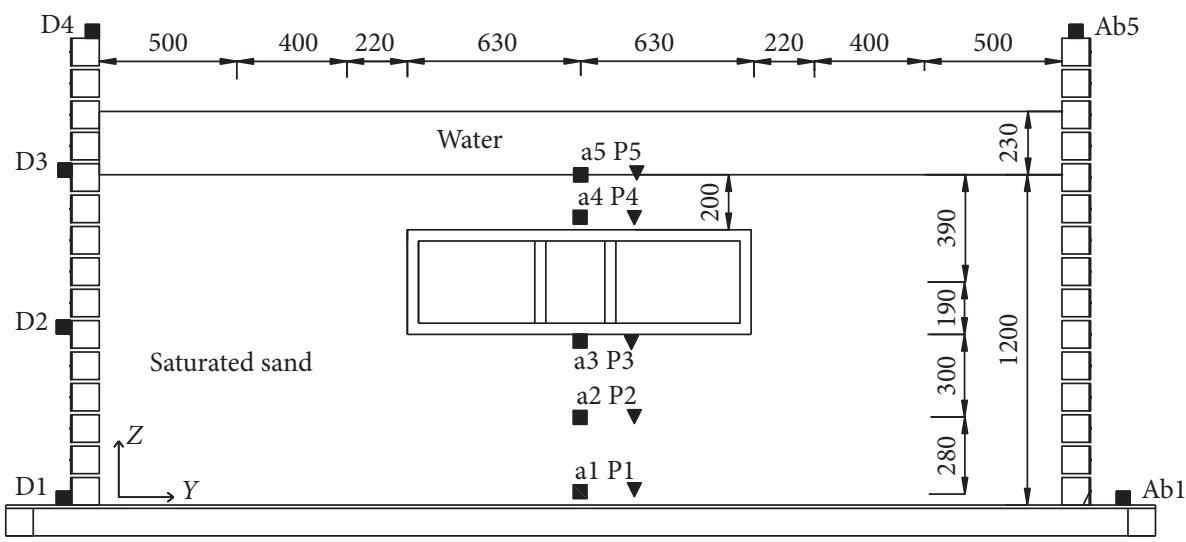

(c)

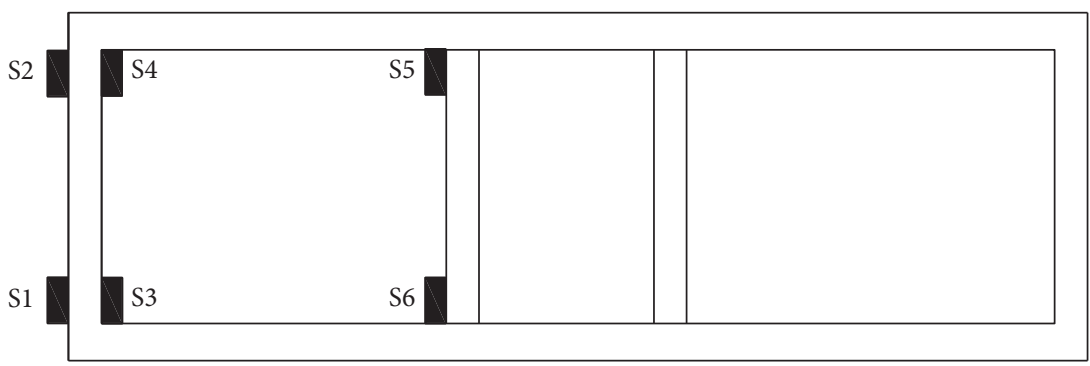

(d)

Figure 5: Sensor layout. (a) Elevation of model. (b) Model plan and observation surface. (c) Elevation layout of acceleration and pore pressure sensors. (d) Strain gauge layout.

3.4. Design of Test Conditions. To study the dynamic response of immersed tunnel under different frequencies and seismic inputs, EL wave and $\mathrm{KB}$ wave were selected as external inputs in this experiment. After each excitation, the frequency was swept with $0.05 \mathrm{~g}$ horizontal white noise, with the input direction $Y$ as horizontal input. The specific test conditions are shown in Table 3. In order to avoid errors of the shaking tables between input and output, the seismic records monitored on the surface of shaking tables were taken as analysis waves. The time-history and Fourier spectra of EL wave and KB wave monitored on the table surface are shown in Figure 6.

\section{Experimental Results and Analysis}

To comprehensively analyze the influence of tunnel stiffness on the surrounding soil layer, the acceleration, pore pressure, and structural strain of the soil layer in observation plane 1 are compared and analyzed in this section.

4.1. Contrast Analysis of Soil Acceleration Time History. To study the influence of tunnel stiffness on the surrounding soil layer, the acceleration time-history of measuring points 
TABLE 3: Test conditions.

\begin{tabular}{lccc}
\hline Loading order & Input wave type & Input direction & Peak acceleration (g) \\
\hline 1 & EL-1 & $Y$ & 0.1 \\
2 & KB-1 & $Y$ & 0.1 \\
3 & EL-2 & $Y$ & 0.2 \\
4 & KB-2 & $Y$ & 0.2 \\
5 & EL-3 & $Y$ & 0.4 \\
6 & KB-3 & $Y$ & 0.4 \\
\hline
\end{tabular}

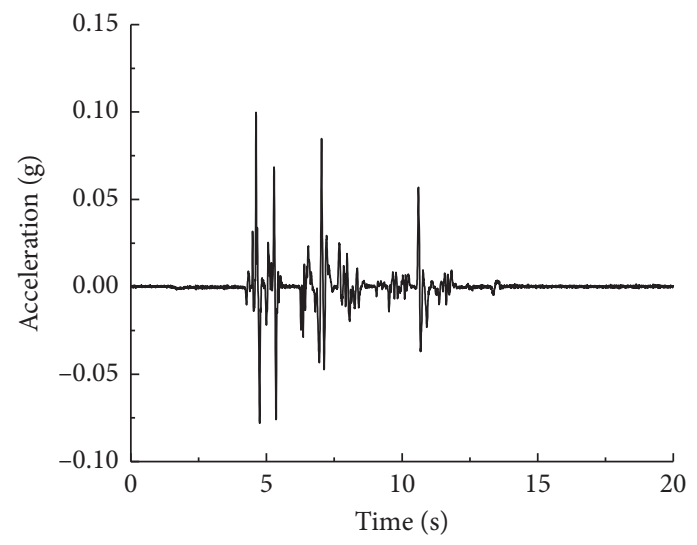

(a)

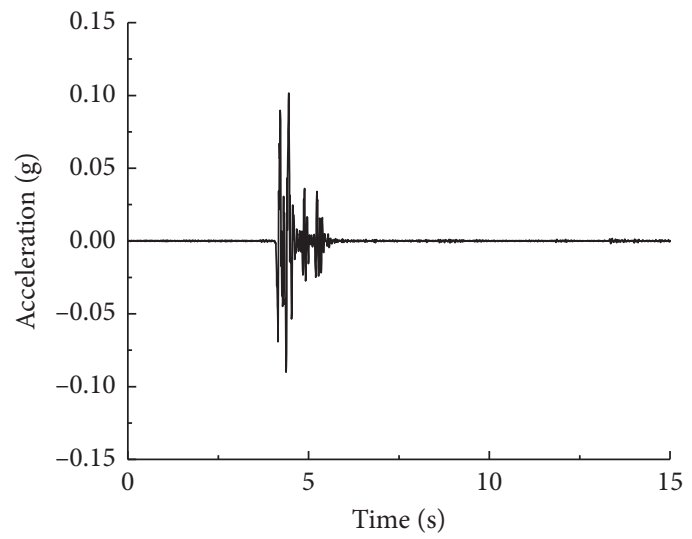

(c)

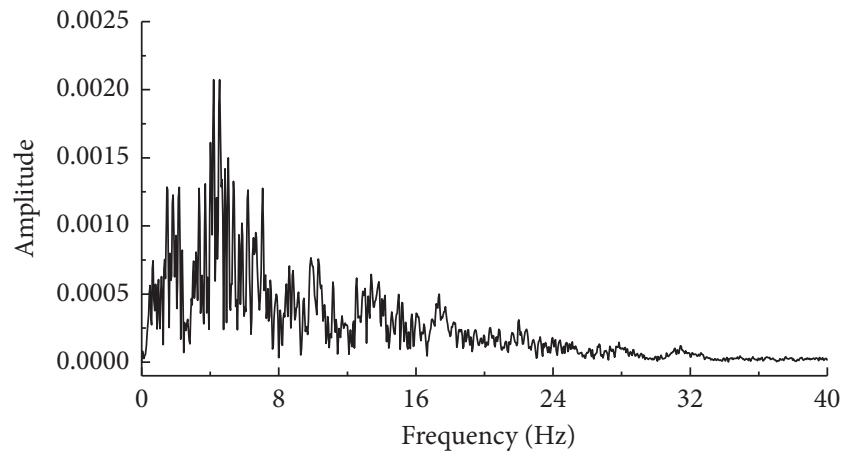

(b)

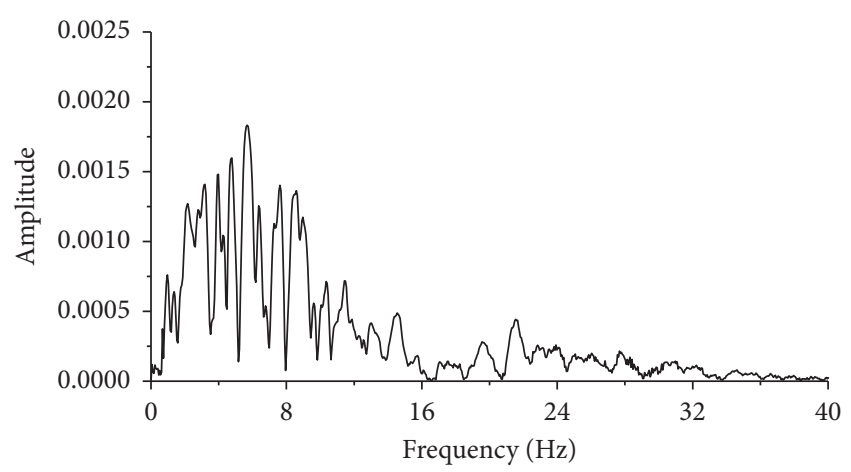

(d)

FIGURE 6: Excitations during testing. (a) EL wave time-history curve. (b) Fourier spectra of EL wave. (c) KB wave time-history curve. (d) Fourier spectra of KB wave.

a1, a2, a3, a4, and a5 in observation plane 1 is selected for analysis (the acceleration sensor at measuring point a 2 was damaged, so no acceleration time-history curve is given). In view of the length, the acceleration response of the soil layer under EL-3 wave input is given in this paper, as shown in Figure 7.

As can be known from Figure 7,

(1) In the same position, the acceleration peak value of the soil layer in test 1 was similar to that in test 2 while, in test 3 , except for the fact that the acceleration peak value of a1 was slightly different from the other two experiments, the acceleration peak values in other positions were quite different. For example, in test 3 , the acceleration peak value of a3 was 1.7 times and 1.3 times smaller than that of test 2 and test 1 , respectively, while the acceleration peak value of a4 was about 1.75 times and 1.65 times smaller than that of test 2 and test 1 , respectively. That was mainly because the larger stiffness of the tunnels in test 3 limited the response of the surrounding soil layers. However, the acceleration peak value of a5 was 2 times and 1.9 times larger than test 2 and test 1 , respectively. The main reason is that the effective stress of soil layer in test 1 and test 2 decreases and soil liquefaction occurs under the action of large amplitude seismic wave. The liquefied soil layer acted as a damping layer to reduce the acceleration peak value of the soil layer (a5). However, in test 3 , the liquefaction of the soil layer was hindered 

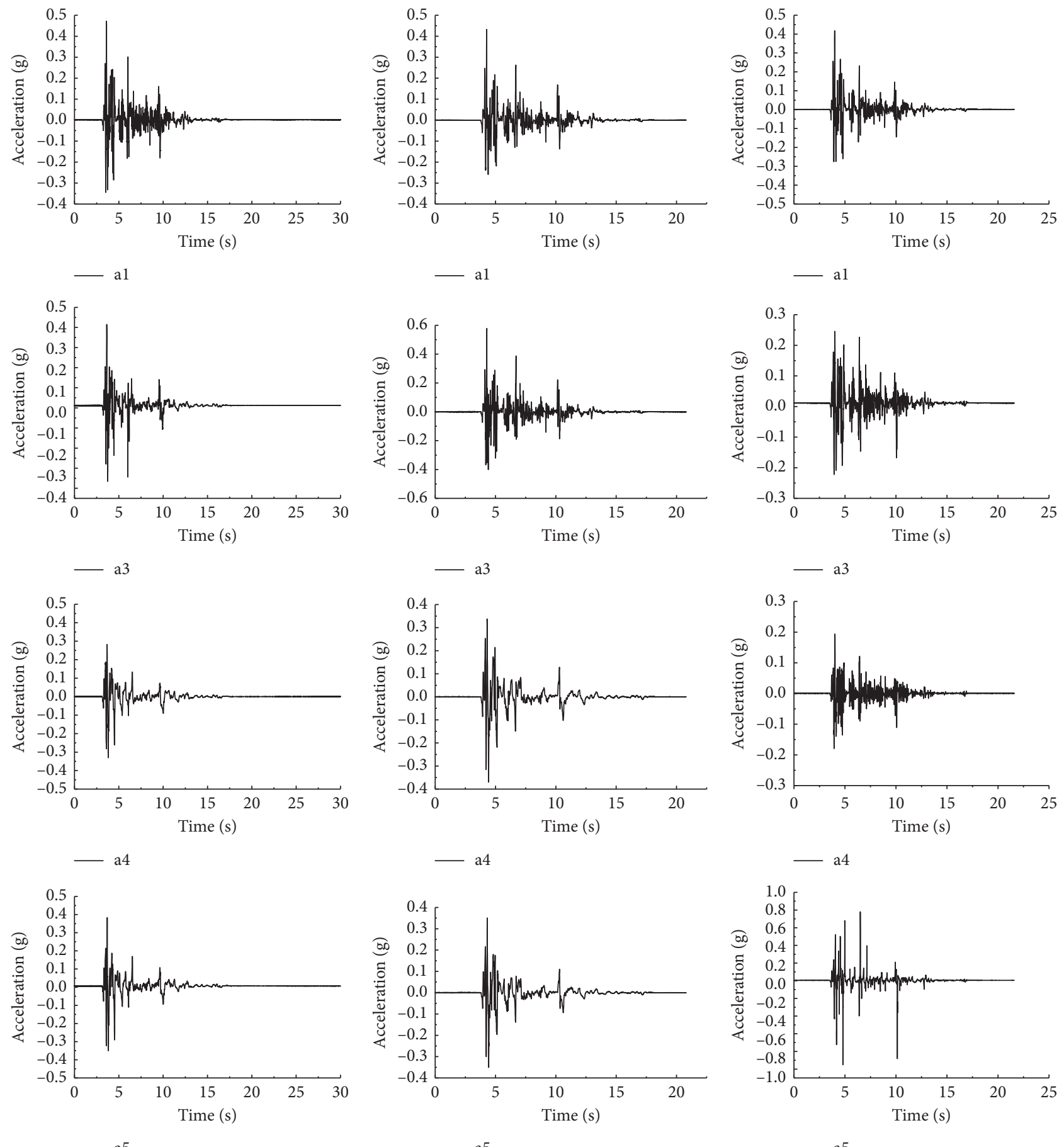

(a)

(b)

(c)

Figure 7: Accelerated response of soil layer under EL-3 wave input. (a) Test 1. (b) Test 2. (c) Test 3.

due to the larger rigidity and weight of the tunnel, so the acceleration peak value of test point a5 in test 3 increased.

(2) Comparing the acceleration time-history curves of a5 in the three groups of tests, it can be known that tunnels can affect not only the acceleration amplitude of the surrounding soil layer, but also the shape of the acceleration time-history curve. The larger the structural rigidity is, the greater the shape change of the acceleration time-history curve of the soil layer is, which means the filtering effect is more obvious.

(3) Comparing the three groups of tests, it can be concluded that the acceleration responses of soil layers in test 1 and test 2 were similar. If the seismic performance of underground structures is analyzed 
by using the response displacement method and the free strain method, the results of calculation with smaller tunnel stiffness are more accurate. In other words, with larger tunnel stiffness, the influence on the acceleration peak values of surrounding soil would be larger.

4.2. Contrast Analysis of the Acceleration Fourier Spectrum of Soil Layer. For exploring the influence of tunnel stiffness on soil dynamic characteristics, the time-history curves of the three groups were analyzed after Fourier transform. Only the test condition of EL-3 wave is analyzed. The acceleration Fourier spectrums of the three groups are shown in Figure 8.

It can be seen from Figure 8 that, in the process of vertical propagation of EL-3 wave, evident low frequency concentration and amplification effect occurred in the frequency spectrums of soil layer in tests 1 and 2. For example, the predominant frequencies of a 4 and a 5 were lower than that of al in tests 1 and 2. That is because with pore water pressure increasing and effective stress decreasing, the effective stiffness of soil layer dropped, which changed the predominant frequency of soil layer from high to low. However, the predominant frequency of measuring points in test 3 remained stable, mainly because with tunnel stiffness increasing, the limitation of the surrounding soil increased and the shear deformation of soil layer was smaller. Besides, the weight of the tunnels in test 3 was larger than that of saturated sand with the same volume so that the effective force of soil layer at the tunnel bottom increased. That is why the effective stiffness did not decrease excessively in the shaking process.

4.3. Contrast Analysis of the Acceleration Amplification Coefficient of Soil Layer. To reflect the propagation law of seismic waves in soil more accurately, the soil layer measuring point a1 in the three groups of tests was taken as the acceleration reference point for research, and the amplification factors of soil layers at different positions were defined based on this. The acceleration amplification factors of the soil layers in the three groups of experiments are shown in Figures 9 and 10.

The following can be seen from Figure 9 .

(1) Under excitation EL wave, the acceleration amplification coefficient of soil layer in test 1 was between 0.71 and 1.48. When the input amplitude of the seismic wave was $0.1 \mathrm{~g}$ and $0.2 \mathrm{~g}$, the acceleration amplification coefficient of the soil layer increased with the decrease of the buried depth of the soil layer, but the acceleration amplification coefficient of the soil layer at the same position decreased with the increase of the input amplitude of the seismic wave. Although the soil layer had not yet reached liquefaction, with the increase of the input amplitude of the seismic wave, the pore pressure of the soil layer increased with the effective stress of the soil layer decreasing. As the input amplitude of the seismic wave increased to $0.4 \mathrm{~g}$, the pore pressure of the soil layer continued to increase. The soil layer liquefied at this time, with the stiffness of soil layer decreasing, and absorbed the seismic energy, so the acceleration amplification coefficient of the soil layer decreased with the decrease of the buried depth of the soil layer.

(2) In test 2, the acceleration amplification coefficient of the soil layer was between 0.82 and 1.43 . When the seismic wave input amplitude was $0.1 \mathrm{~g}$, the pore pressure in the soil layer was relatively small, and the soil layer had not yet reached liquefaction. Therefore, the acceleration amplification coefficient in the soil layer increased with the decrease of the buried depth of the soil layer. When the input amplitude of the seismic wave increased to $0.2 \mathrm{~g}$ and $0.4 \mathrm{~g}$, the pore pressure of the upper soil layer of the structure increased rapidly. With the effective force decreasing, the liquefaction of soil layer resulted in the consumption of partial seismic energy. As the weight of the soil layer at the lower part of the structure was larger than that of the soil layer with the same volume, the effective stress of the soil layer at the lower part of the structure increased. Moreover, the rigidity of the structure had a restraining effect on the lower soil layer so that the lower soil layer of the structure was hard to liquefied, only with subtle decrease of effective stiffness of soil layer. That is why the acceleration amplification coefficient of the soil layer in test 2 decreased firstly and then increased with the decrease of the depth of the soil layer.

(3) In test 3, the acceleration amplification coefficient of the soil layer was between 0.6 and 2.1. When the input amplitudes of seismic waves were $0.1 \mathrm{~g}, 0.2 \mathrm{~g}$, and $0.4 \mathrm{~g}$, respectively, due to the large rigidity of the tunnel restraining the seismic response of the soil layer nearby, the acceleration of the soil layer reduced. Under the joint action of tunnel rigidity and weight, although the pore pressure of soil layer increased with the increase of seismic wave input amplitude, the soil layer had not yet reached liquefaction. Therefore, the acceleration of the surface soil layer increased with the increase of the seismic wave input amplitude. That is why the acceleration amplification coefficient of the soil layer in test 3 decreased firstly and then increased with the decrease of the soil depth.

(4) Compared with the acceleration amplification coefficient curves of the three groups, it can be summarized that when the input amplitude of seismic wave is $0.4 \mathrm{~g}$, the variation law of the acceleration amplification coefficient of the upper soil layer of the tunnel structure is the same, but the reasons differ. For example, in tests 1 and 2, the acceleration amplification coefficient of the soil layer decreased with the decrease of the buried depth of the soil layer mainly because the pore pressure of soil layer ascended and the effective force descended, leading to the decrease of the acceleration of soil layer. However, in test 3 , the large rigidity of the tunnel 

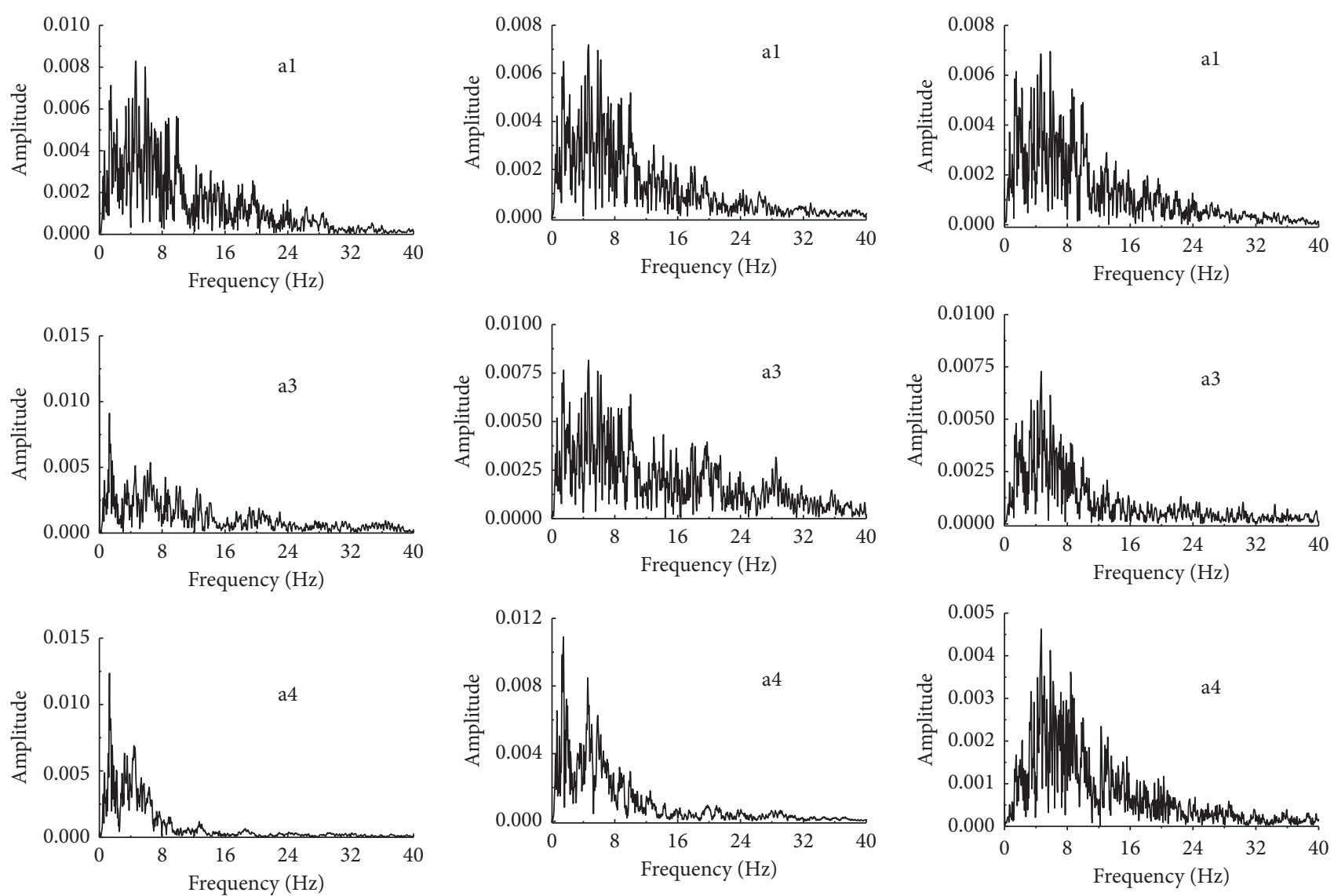

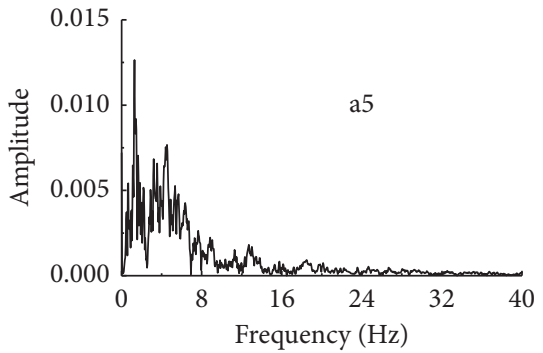

(a)

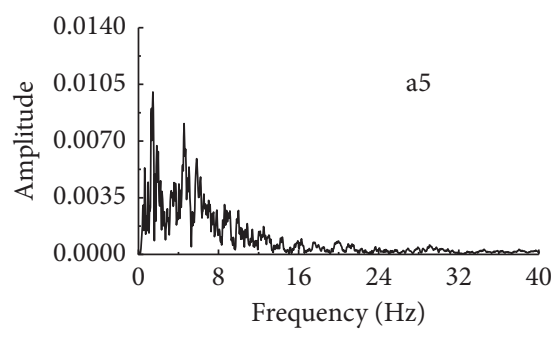

(b)

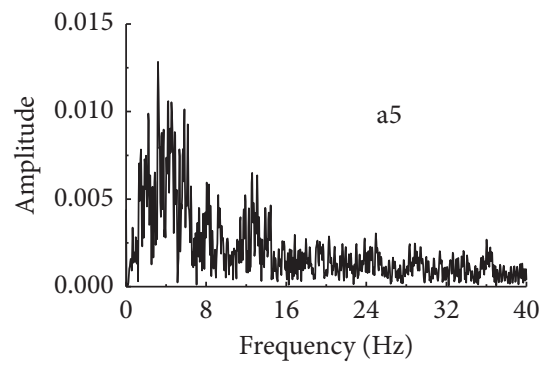

(c)

Figure 8: Acceleration Fourier spectrum of EL-3 wave. (a) Test 1. (b) Test 2. (c) Test 3.

restrained the response of the soil layer and reduced the acceleration of the soil layer. In test 3 , the acceleration amplification coefficients (a3 and a4) of the soil layer nearby the tunnel structure were smaller than those of test 1 and test 2 in the same position.

As can be known by comparing Figures 9 and 10, under the action of $\mathrm{KB}$ wave, the acceleration amplification law of soil layer in tests 1,2 , and 3 was basically the same as that under the action of EL wave, so it will not be repeated in this paper.

4.4. Analysis of Soil Pore Pressure. Under the action of earthquake load, the pore water pressure of the sand layer rises rapidly. The superporosity ratio is generally used to judge whether the sand layer is in a safe state at this moment.
As shown in formula (2), when the superporosity ratio is up to 1.0 , the soil layer liquefies:

$$
\operatorname{ERRP}=\frac{U}{\sigma} .
$$

In formula (2), ERRP is the superporosity ratio, with $U$ representing the superpore water pressure and $\sigma$ representing the effective stress. In this section, with the input amplitude of ground motion being $0.4 \mathrm{~g}$, the pore pressure time-histories of soil layers in three groups of tests are compared and analyzed, as shown in Figures 11 and 12 .

It can be obtained by comparing Figures 11 and 12:

(1) Under excitation EL wave or KB wave, the superpore pressure ratio of the soil layer in the three tests increased with the decrease of the buried depth of 


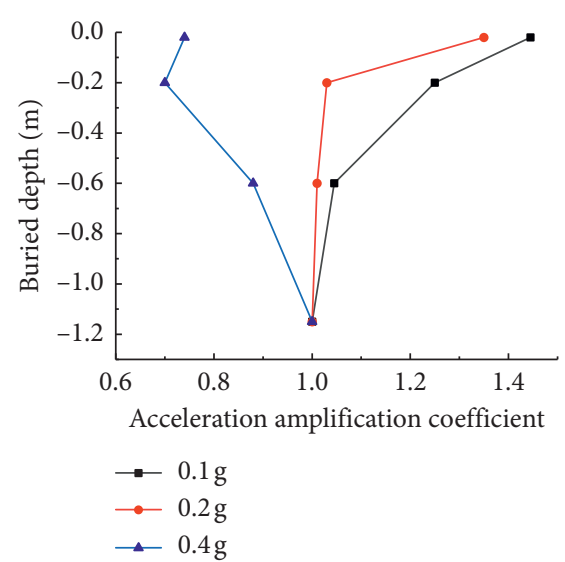

(a)

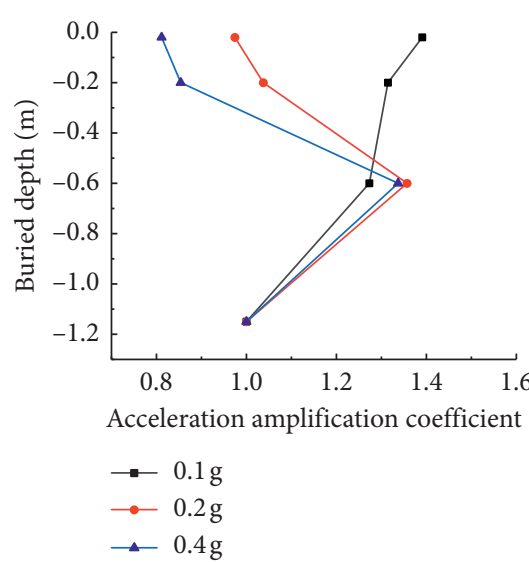

(b)

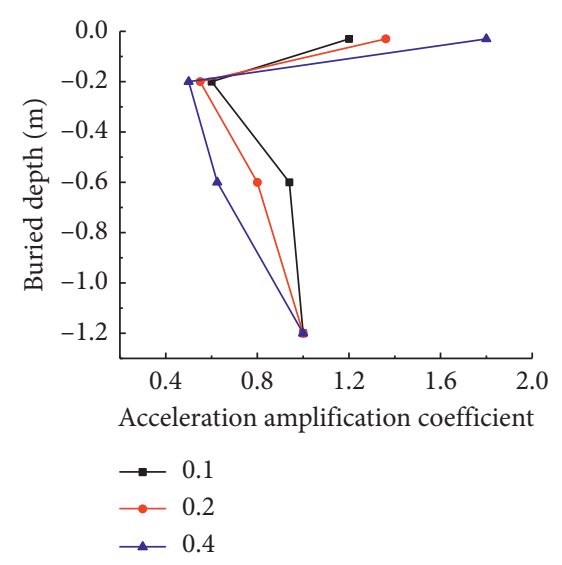

(c)

Figure 9: Acceleration amplification coefficient of soil for three groups of tests under EL wave. (a) Test 1. (b) Test 2. (c) Test 3.

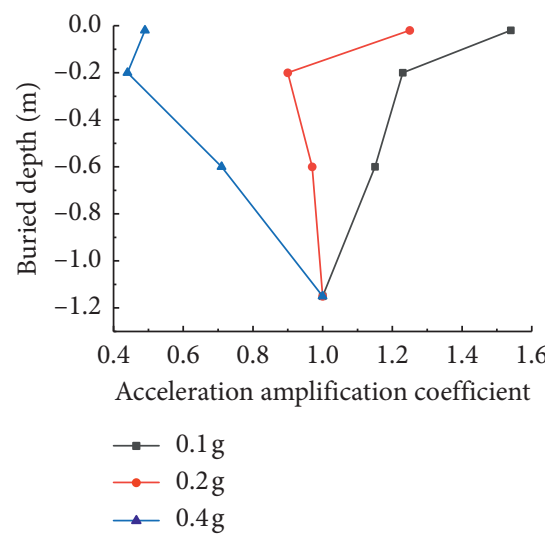

(a)

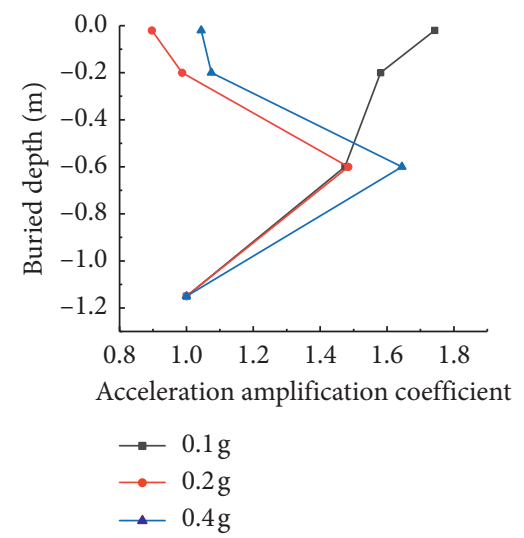

(b)

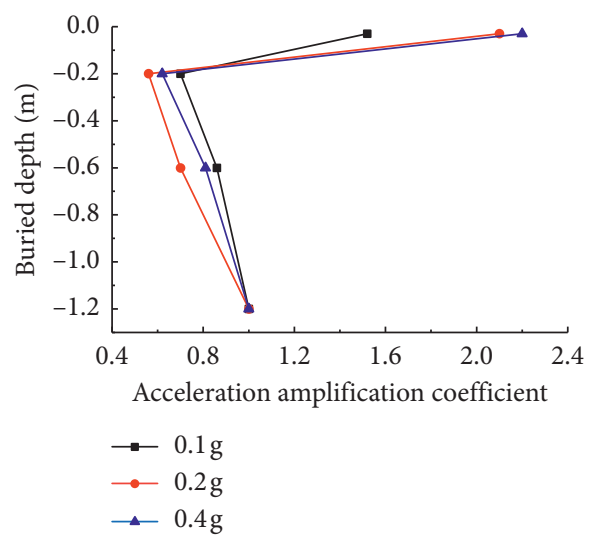

(c)

Figure 10: Acceleration amplification coefficient of soil for three groups of tests under KB wave. (a) Test 1. (b) Test 2. (c) Test 3.

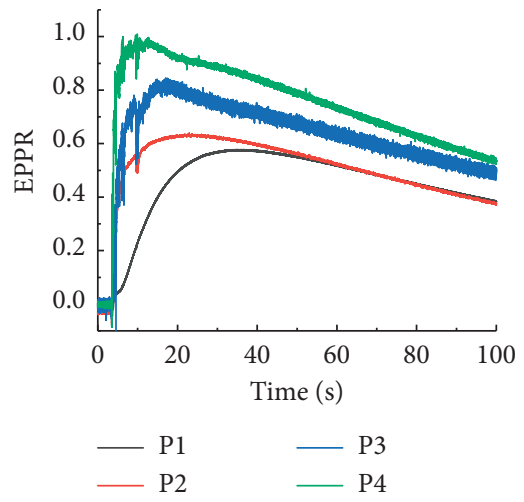

(a)
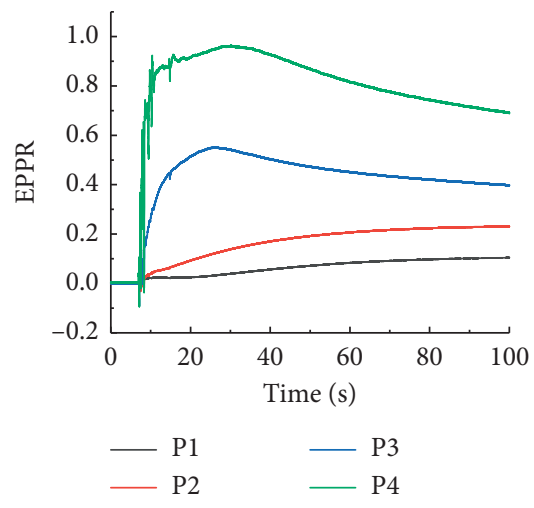

(b)
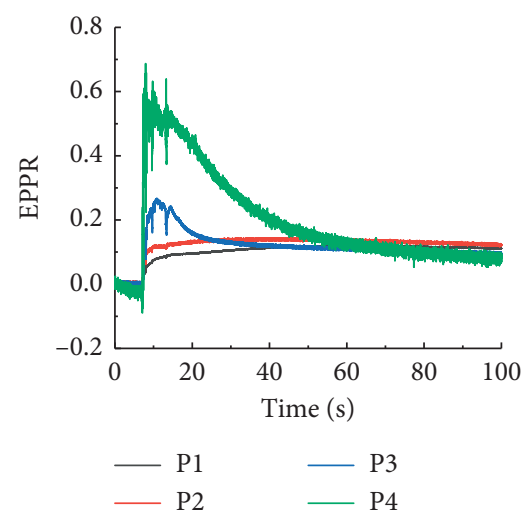

(c)

Figure 11: Pore pressure time-history curves of soil layers in three groups of tests under EL wave. (a) Test 1. (b) Test 2. (c) Test 3.

soil layer. Besides, the closer to the surface, the larger the superpore pressure ratio. That is because the shear deformation of the soil layer becomes larger towards its top surface.
(2) Under excitation EL wave, the superpore pressure ratio of each measuring point in the soil layer was obviously larger than that under $\mathrm{KB}$ wave. This shows that the characteristics of ground motion 


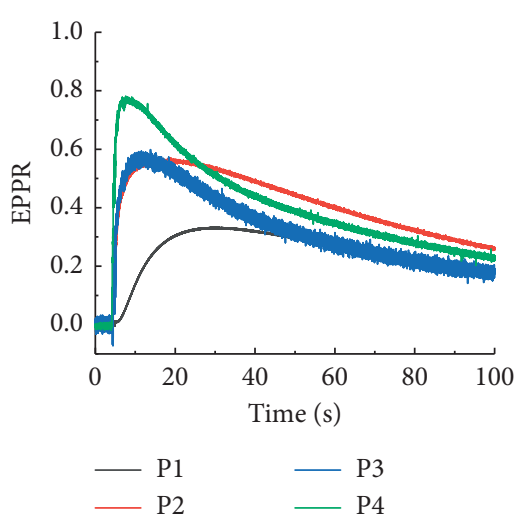

(a)

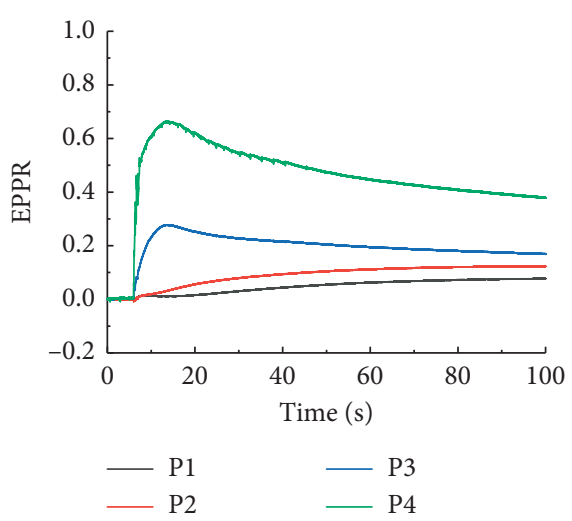

(b)

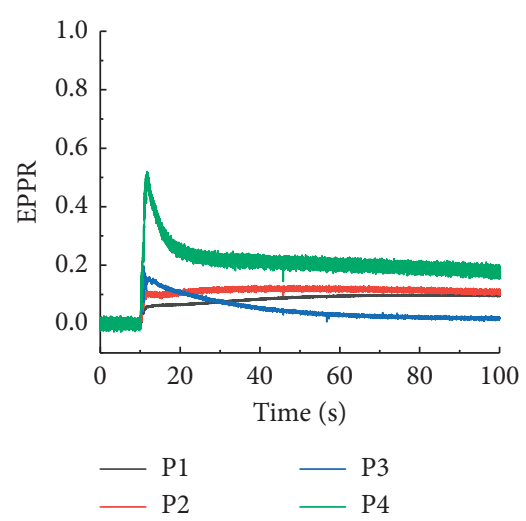

(c)

Figure 12: Pore pressure time-history curves of soil layers in three groups of tests under KB wave. (a) Test 1. (b) Test 2. (c) Test 3.

affect the development law of pore pressure in the soil layer.

(3) Whether under excitation EL wave or KB wave, the superstatic pore pressure at the soil layer measuring point in test 1 at the same position was larger than that in test 2 and test 3. For example, under excitation EL-3 wave, the pore pressure of test point P3 in test 1 was 2.1 times and 3.2 times larger than that in test 2 and test 3 , respectively. The pore pressure of P4 in test 1 was 1.2 times and 1.7 times larger than that of test 2 and test 3 , respectively. It can be concluded that with the structural stiffness smaller, the pore pressure of soil layer and free site soil layer is closer because smaller structural stiffness means smaller restraints on soil layer, which means smaller interaction between the soil and the structures. Moreover, the pore pressure of the upper soil nearby the structures is closer to that of the free site soil than the lower one. That is because the weight of the structures with the same volume is larger than the soil, resulting in the increased effective force of the lower soil.

(4) In the three tests, the increase and dissipation of pore pressure at each measuring point of the soil layer varied when it comes to time. For example, under excitation EL-3 wave, the pore pressure of each measuring point in test 1 , test 2 , and test 3 rose sharply within 5-20s, 7-22s, and 8-10 s, respectively. However, the dissipation rate of pore pressure at each measuring point in test 3 is the highest while that in test 1 took the second place, with test 2 being the slowest. This is because the soil layer in test 3 only liquefied to a lesser extent, and the drainage channels (pore) of soil layer were not yet full of water. Therefore, the pore water could rapidly fill the pores in the shaking process, so that the water was drained fast. However, the soil layers both in test 1 and test 2 liquefied to a high extent, with the most of drainage channels full of water. Moreover, the tunnels in test 2 hindered the dissipation of pore pressure in soil layers. Therefore, in the three tests, the soil pore pressure dissipation in test 3 was faster than the other two tests.

4.5. Strain Analysis of Tunnel Structure. To study the influence of tunnel stiffness on its internal force under earthquake action, the strain gauges of the intermediate section of the structure in test 3 and intermediate section in test 2 are selected for comparison. Among those, the S6 strain gauge in test 3 was damaged and no data was collected. The strain time-histories of the remaining effective strain data are shown in Figure 13, and the strain peaks are shown in Tables 4 and 5 .

The following can be obtained from Tables 4 and 5:

(1) The strain peak value of each measuring point in test 2 and test 3 increased with the increase of the input amplitude of seismic wave. For example, in test 2, when the input amplitude of EL wave increased from $0.2 \mathrm{~g}$ to $0.4 \mathrm{~g}$, the strain amplitude of measuring point S2 increased from 51.13 to 100.89 while, in test 3, the strain amplitude of S2 increased from 27.13 to 45.01 . Under excitation $\mathrm{KB}$ wave, each measuring point also shared the same variation law.

(2) Whether under excitation EL wave or KB wave, the upper strain amplitude of the tunnel structure in tests 2 and 3 was larger than the lower one. For example, in test 2 , under excitation EL-1 wave, the strain peak value of S2 was 33.87, and the strain peak value of S1 was 22.6. However, the strain peak values of S4 and S5 were greater than S3 and S6, respectively. That is mainly because the relative displacement of the upper soil of the structure is larger than the lower one. Therefore, the design of the upper structure deserves more attention in the process of tunnel design.

(3) On the one hand, under the same ground motion input, the strain amplitude of each measuring point in test 2 was larger than that of the corresponding measuring point in test 3 , and the plastic deformation of the structures in test 2 was larger than test 3 (Figure 13), which resulted from the smaller 

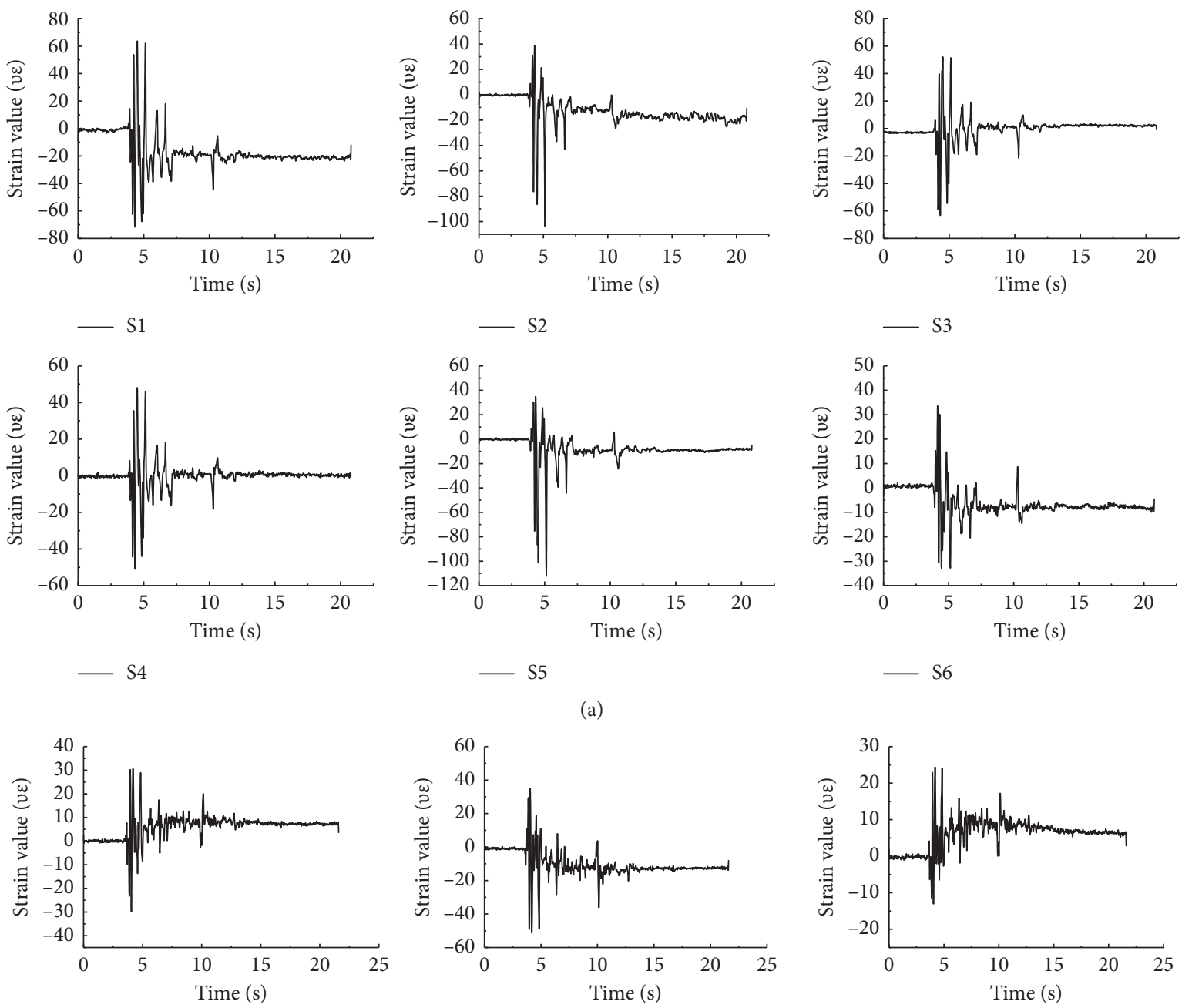

(a)
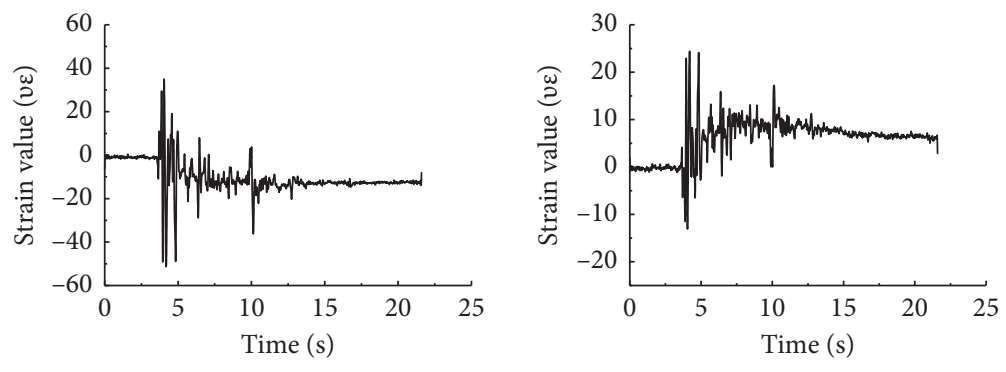

$-\mathrm{S} 1$

$-\mathrm{S} 2$
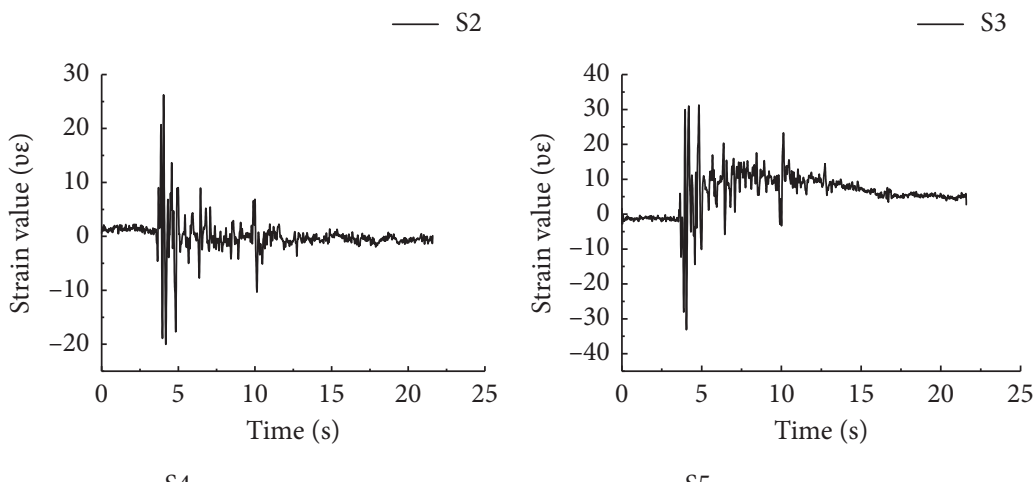

(b)

FIgURE 13: Structural strain time-history of test 2 and test 3 under EL-3 wave. (a) Test 2. (b) Test 3.

TABLE 4: Strain peak of the structure under EL wave.

\begin{tabular}{lllcrr}
\hline Measuring point & \multicolumn{2}{c}{ Test 2} & & Test 3 \\
EL-2 & EL-1 & 14.17 & 19.94 \\
\hline S1 & EL-1 & 36.80 & 70.74 & 18.20 & 27.13 \\
S2 & 22.60 & 51.13 & 100.89 & 9.23 & 14.86 \\
S3 & 33.87 & 34.01 & 50.55 & 11.51 & 15.41 \\
S4 & 21.71 & 41.25 & 60.87 & 15.38 & 21.83 \\
S5 & 28.98 & 42.97 & 108.15 & 26.41 \\
S6 & 28.58 & 27.14 & 36.37 & & 25.27 \\
\hline
\end{tabular}


TABLE 5: Strain peaks of structures under KB wave.

\begin{tabular}{lllllr}
\hline Measuring point & & Test 2 & & Test 3 \\
KB-2 & KB-1 & 11.91 & 17.98 \\
S1 & KB-2 & KB-3 & 75.53 & 15.85 & 21.62 \\
S2 & 12.30 & 35.86 & 91.57 & 7.74 & 19.95 \\
S3 & 24.57 & 47.50 & 30.17 & 5.84 & 13.29 \\
S4 & 14.87 & 37.95 & 76.56 & 13.51 \\
S5 & 20.02 & 40.26 & 38.25 & 12.64 & 19.34 \\
S6 & 15.13 & 26.67 & & \\
\hline
\end{tabular}

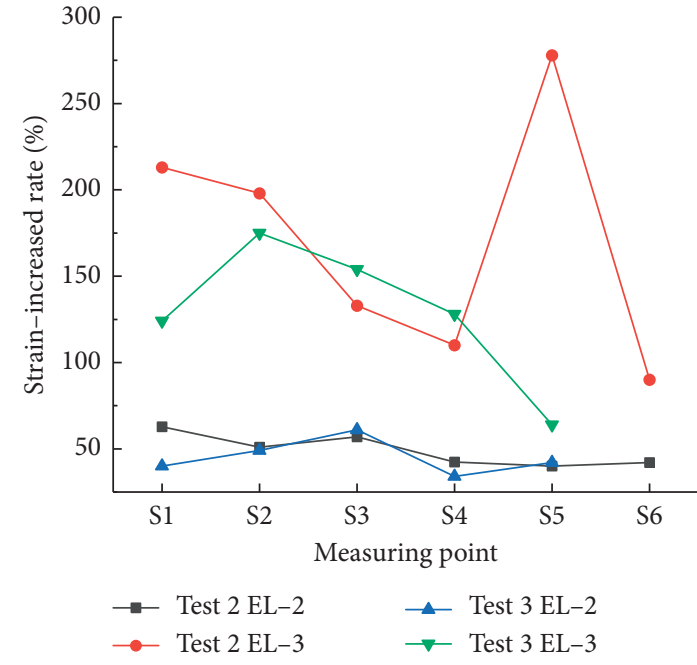

(a)

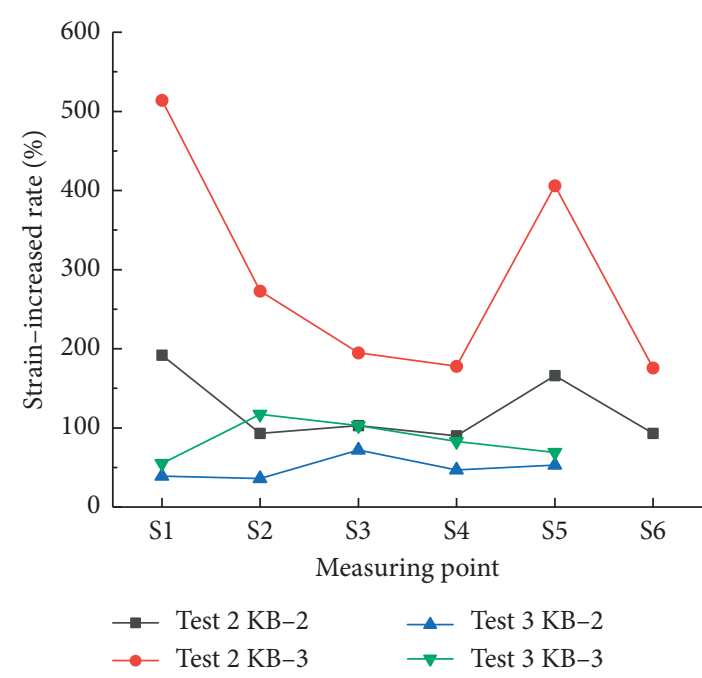

(b)

FIgURE 14: Comparison chart of strain growth rate of structures under different test conditions.

stiffness of the structures in test 2 than test 3 . Under the same load, the structures deform more with smaller stiffness. Once the deformation goes beyond elastic deformation, unrecoverable plastic deformation happens. That is why the strain time-history curves do not go back to the original point at the end of shaking. On the other hand, the tunnels in test 2 were more adaptable to the surrounding soil motion: under excitation EL-2 wave, the strain peak value of S2 in test 2 was 51.12 while that was 27.13 in test 3; under excitation KB-2 wave, the strain peak value of S2 in test 2 was 47.50 while that was 21.62 in test 3. The remaining points in test 2 shared the same variation law with those in test 3 .

(4) Under the same seismic wave input, the strain of the tunnel structure caused by EL wave was clearly larger than that by KB wave. It suggests that the characteristics of ground motion input influence the dynamic response of tunnels greatly. For example, in test 2, the strain amplitude of measuring point $S 1$ caused by EL-1 wave was 22.60 , with that caused by KB-1 wave being 12.30 , while, in test 3 , the strain amplitude of $\mathrm{S} 1$ caused by EI-1 wave was 14.17, with that caused by KB-1 wave being 11.91 . Other measuring points shared the same characteristics.
To better reflect the growth process of structural strain in the tests, EL-1 and KB-1 in the two groups of tests are, respectively, taken as reference objects to analyze and study the structural strain amplitude growth of the two groups under test conditions EL-2, EL-3, KB-2, and KB-3. The results are shown in Figures 14 and 15.

The following can be obtained by comparing Figure 14: (1) under the same seismic wave input, the strain growth rate of the structure in the two groups of tests increased with the increase of the ground motion amplitude. (2) Under excitation EL-2, the strain growth rate of each measuring point in test 2 and test 3 was similar while under excitation EL-3, the strain growth rate of multiple measuring points in test 2 was significantly higher than that in test 3 . Among them, the growth rates of $\mathrm{S} 1$ and $\mathrm{S} 5$ in test 2 were the highest while the growth rate of S4 was the lowest; in test 3, the growth rate of S2 was the highest while that of S5 was the lowest. (3) Under excitations KB-2 and KB-3, the strain growth rate of each measuring point in test 2 was significantly higher than that in test 3. Under excitation KB-3, the growth rates of $S 1$ and S5 in test 2 were the highest while that of S4 was the lowest; in test 3, the growth rate of S2 was the highest while that of measuring point 5 was the lowest.

The following can be known by comparing Figure 15: in test 2, under excitation of the same magnitude of seismic wave, the strain growth rate of each measuring point of the 


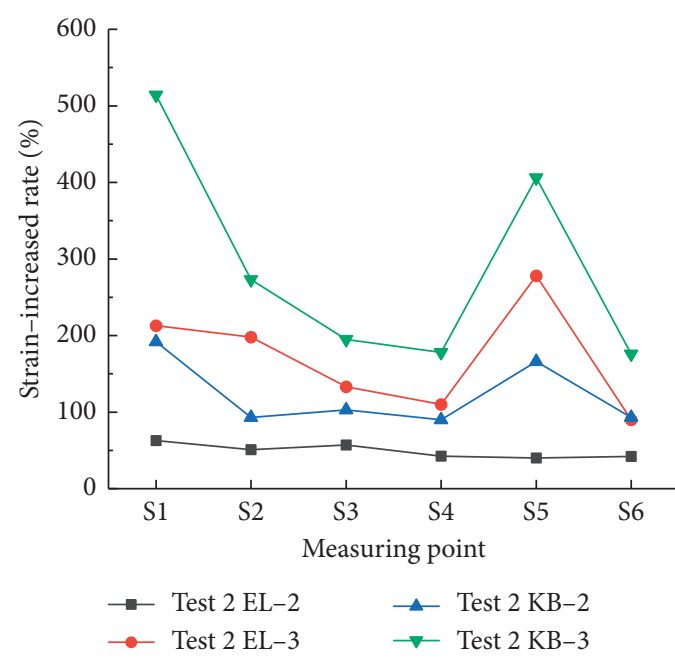

(a)

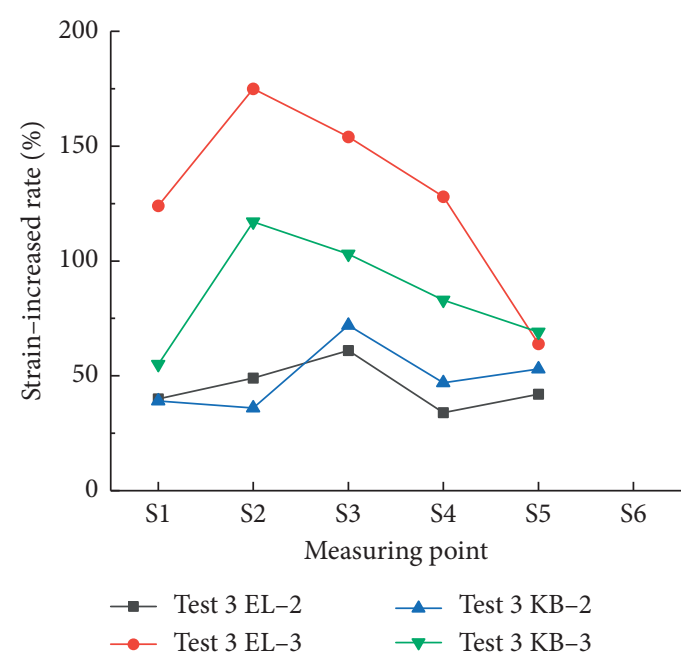

(b)

FIGURE 15: Comparison chart of strain growth rate of structures under different seismic wave inputs.

structure caused by KB wave was significantly higher than that caused by the EL wave. In test 3, the strain growth rate of each measuring point of the structure in working conditions EL-2 and KB-2 was similar while the strain growth rate of each measuring point of the structure in working condition EL-3 was larger than that in working condition KB-3.

It can be concluded from the analysis mentioned above that the strain growth rate of the structure increases with the increase of the seismic wave amplitude, which is independent of the rigidity of the structure while the strain growth rate of the structure is related to the rigidity of the structure. Generally speaking, the strain growth rate of the structure with small rigidity is higher under the action of moderate earthquakes. Under the same ground motion, the strain growth rate of each measuring point of the structure is different. Namely, there is a spatial effect on the growth of structural strain. Under the action of the same amplitude and different ground motions, the growth rate of each measuring point at the same position is different. In other words, the ground motion characteristics have a certain influence on the strain growth rate of the structure.

\section{Conclusion}

Through shaking table tests, the pore water pressure, acceleration time-history, and structural strain in liquefiable soil layers under three different working conditions are analyzed, and the following conclusions are obtained:

(1) The tunnel stiffness influences the propagation of seismic wave in soil. The greater the stiffness of the tunnel, the greater is the influence on the dynamic characteristics of the surrounding soil. Therefore, designers should pay attention to the influence of increased structural stiffness on the dynamic characteristics of local sites.

(2) Tunnels would hinder the liquefaction of the surrounding soil locally. The influence would be more significant with larger stiffness of tunnels. Thereby, the antiliquefaction standard could be relaxed when designing the soil antiliquefaction measurements. Nevertheless, the range of soil antiliquefaction influenced by the tunnel stiffness needs further study.

(3) With smaller stiffness of tunnels, the change rules of the pore pressure of surrounding soil are more similar to those of the free site soil layers.

(4) It is found in the shaking process that the upper part of the structures, especially the upper part of the stele in the structure, which is the unfavorable part of the tunnel, should be reinforced when designing. Under the ground motion input with the same acceleration peak, less stiff tunnels with larger strain peak are more adaptable to the surrounding soil motion. Besides, the calculation about the structural seismic characteristics would be more accurate by response displacement method and free strain method. However, with smaller stiffness of tunnels, the plastic deformation would be larger and may lead to water leak, which deserves attention to the waterproof requirements when designing.

(5) The strain growth rate of the tunnel is related to the stiffness of the structure. Generally speaking, under the action of moderate earthquakes, the strain growth rate of the structure with smaller stiffness is higher.

\section{Data Availability}

The data used to support the findings of this study are available from the corresponding author upon request. Contact Ouyang Zhiyong via email id: 52424848@qq.com

\section{Conflicts of Interest}

The authors declare that they have no conflicts of interest regarding the publication of this paper. 


\section{Acknowledgments}

This work was supported by the National Natural Science Foundation of China (Grant nos. 51808259, 51438004, and 51408566) and Colleges Youth Innovative Talents Project of Guangdong Province (no. 2019KQNCX147).

\section{References}

[1] Y. M. A. Hashash, J. J. Hook, B. Schmidt, and J. I.-C. Yao, "Seismic design and analysis of underground structures," Tunnelling and Underground Space Technology, vol. 16, no. 4, pp. 247-293, 2001.

[2] X. Tang and H. W. Huang, "A study on several key topics of shield tunnel lining design," Underground Space, vol. 23, no. 2, pp. 210-215, 2003.

[3] H. X. Jian and X. Y. Hou, "Analysis of relative stiffness between fabricated circular tunnel and soft ground," Chinese Journal of Rock Mechanics and Engineering, vol. 23, no. 13, pp. 2262-2265, 2004.

[4] C. M. S. John and T. F. Zahrah, "Seismic design of underground structures," Tunnelling and Underground Space Technology, vol. 21, pp. 165-197, 1987.

[5] J. Penzien, "Seismically induced racking of tunnel linings," Earthquake Engineering \& Structural Dynamics, vol. 29, no. 5, pp. 683-691, 2000.

[6] B. Peckr, A. J. Hendron, and B. Mohraz, "State of the art of soft ground tunnelling," in Proceedings of the Rapid Excavation and Tunnelling Conference, Chicago, IL, USA, June 1972.

[7] X. B. Yao, C. Z. Qi, and J. Luo, "Effect of relative stiffness on seismic response of underground rectangular structure," Journal of Wuhan University of Technology, vol. 3, no. 35, pp. 93-97, 2013.

[8] L. J. Xu, H. P. Ding, and G. Kong, "Effect of relative stiffness on seismic response of circular tunnels," Earthquake Resistant Engineering and Retrofitting, vol. 5, no. 30, pp. 69-73, 2008.

[9] N.-A. Do, D. Dias, P. Oreste, and I. Djeran-Maigre, "2D numerical investigation of segmental tunnel lining under seismic loading," Soil Dynamics and Earthquake Engineering, vol. 72, pp. 66-76, 2015.

[10] H. Yu, Z. Zhang, J. Chen, A. Bobet, M. Zhao, and Y. Yuan, "Analytical solution for longitudinal seismic response of tunnel liners with sharp stiffness transitionffness transition," Tunnelling and Underground Space Technology, vol. 77, pp. 103-114, 2018.

[11] L. Jiang, J. Chen, and J. Li, "Seismic response of underground utility tunnels: shaking table testing and FEM analysis: Shaking table testing and FEM analysis," Earthquake Engineering and Engineering Vibration, vol. 9, no. 4, pp. 555-567, 2010.

[12] L. J. Tao, P. L. Wang, and J. Bian, "A shaking table test method on the representative subway station structure," Journal of Beijing University of Technology, vol. 32, no. 9, pp. 798-801, 2006.

[13] G. X. Chen, X. Zuo, and Z. H. Wang, "Shaking table method test of subway station strucute under far field and near field ground motion," Journal of Zhejiang University (Engineering Science), vol. 44, no. 10, pp. 1955-1961, 2010.

[14] Y. Tamari and I. Towhata, "Seismic soil-structure interaction of cross sections of flexible underground structures subjected to soil liquefaction," Soils and Foundations, vol. 43, no. 2, pp. 69-87, 2003. 